\title{
The Semantic Models of FACT Clauses in Discourse: A Systemic Functional Perspective
}

\author{
Hongyan Liang ${ }^{1}$ \\ ${ }^{1}$ School of Foreign Languages, Shanxi University, Taiyuan, China \\ Correspondence: Hongyan Liang, School of Foreign Languages, Shanxi University, Taiyuan 030006, Shanxi \\ Province, China. Tel: 86-0351-472-9567. E-mail: lhy.jessie@163.com
}

Received: November 6, 2014 Accepted: December 3, 2014 Online Published: January 27, 2015

doi:10.5539/ijel.v5n1p84 URL: http://dx.doi.org/10.5539/ijel.v5n1p84

\begin{abstract}
This study explores the semantic features of FACT clauses in discourse context within the theoretical framework of Systemic Functional Linguistics. The investigation starts with the exploration of the typical process types occurring in the matrix clause of FACT clause simplex, which is helpful and necessary to display different process types which construe FACT category. Then, the study conducts from the vantage point of semantics in discourse with three semantic models: (i) positive/negative orientation model; (ii) positive/negative reaction model; and (iii) positive/negative evaluation model. The results show that the semantic models of FACT clauses are construed by different process types as well as their contextual factors.
\end{abstract}

Keywords: FACT, projection, Systemic Functional Linguistics, orientation, reaction, evaluation

\section{Introduction}

FACT is a technical term adopted by linguists in the field of Systemic Functional Linguistics (henceforth SFL) as a special category of projection "where the projected clause is not being projected by a verbal or mental process with Sayer or Senser, but comes as it were ready packaged in projected form" (Halliday, 1994/2000, p. 264; Halliday \& Matthiessen, 2004, p. 470). In specific, it is a semantic category which is realized by the lexicogrammatical form of "FACT noun with FACT clause (that-clause, infinitive clause, or gerundive clause) as Qualifier" or simply "FACT clause". However, the adoption of the term "FACT" is argumentative in the field of SFL. Halliday (1994/2000, p. 115) declares that FACT is not used in its exact technical sense. Thompson (1994) states that FACT has nothing to do with "truth". Considering the semantic nature of FACT as the representation of a second-order experience, some scholars also term it as "FACT projection" (Davidse, 1994) or "factual projection" (Forey, 2009).

Actually, the terms outlined above are sometimes used mutually, such as "factive clause" used by Quirk et al. (1972, p. 842), "factual Carrier" adopted by Halliday \& Matthiessen (2004, p. 615). In order to achieve continuity with the existing studies, this study adopts the capitalized terms "FACT", "FACT clause", "embedded FACT clause" or "FACT projection", which are generally used in SFL because of their functional semantic orientation.

Structurally, a FACT clause, as a constituent element, enters into another clause which is usually referred to as a matrix clause. The structural configuration of the matrix clause and the embedded FACT clause is a simple clause in nature. Contrasted with the clause complex in which two clauses are combined with tactic relations, the simple clause with an embedded clause can be described as a "clause simplex" (Halliday \& Matthiessen, 2004, p. 365; Davidse, 1994, p. 276) or "simplex clause" (Eggins, 2004, pp. 255-256; Butler, 2003). In order to name the lexicogrammatical pattern of FACT concisely, we adopt the term "FACT clause simplex" to refer to the structural organic configuration of matrix clause and FACT clause as a whole in this study. For example,

(1) But the fact [[ that an error can be explained, even an unavoidable error, ]] does not mean that it thereby ceases to be an error. (BNC BMA, 1434)

Example (1) exemplifies a structural organic configuration of FACT clause simplex, in which the embedded clause that an error can be explained, even an unavoidable error in the notational convention [[ ]] is a FACT clause and the clause But the fact does not mean that it thereby ceases to be an error is a matrix clause.

As is well known, all linguistics is the study of meaning and all meaning is function in a context (Firth 
1935/1957). In this study, FACT is mainly observed in the discourse context. Specifically, we focus on the relationship between the process types of the FACT clause simplexes in terms of transitivity and the semantic features of FACT in discourse from the perspective of SFL. Through the semantic account of FACT in English, we envisage how the expressive meanings of FACT category are construed by its contextual factors as well as the different process types in the matrix clause.

\section{Previous Studies}

In the literature to date, FACT in discourse presents diversities of semantic choices. For example, Davidse (2003) outlines three general discourse schemata: (i) cognitive or emotional "acceptance"/"non-acceptance" of a pre-existent proposition; (ii) positive or negative emotional reaction to a pre-existent proposition, and (iii) evaluation of the significance of a pre-existent proposition, based on the three categories of FACT: (i) speaker-FACT (s-FACT); (ii) Processer-FACT (P-FACT); (iii) speaker-and-Processer-FACT (s-P-FACT). The first schema is typically associated with s-P-FACT category. The second general discourse schema is the one typically associated with pure P-FACT category. The third schema is primarily related with s-FACT category. In Davidse's empirically-driven investigation, FACT-proposition has emerged as a clause which does not have the feature "presupposed true by the speaker", but the more abstract feature of "proposition which is pre-existent to the relation in which it participates" (2003, p. 126). Its separate relation with the matrix clause allows its FACT status to be inferred as either the speaker, or the Processer, or both being committed to its truth.

In addition, Francis (1993), Hunston \& Francis (2000) and Hunston (2011) conduct the phraseological studies on the fact that. Francis (1993, p. 154) notes that the propositions following the fact that sometimes contain a modal verb, suggesting that something labelled fact may not actually be a FACT. Hunston (2011, pp. 113-116) further singles out seven groups of semantic sequences of FACT based on the corpus-based investigation of the phraseology the fact that:

Group 1: FACT is the basis for a practical outcome or reasoning

Group 2: FACT explains something

Group 3: FACT is the cause of a problem or its solution

Group 4: Something uses or assumes a FACT

Group 5: Be aware or unaware of a FACT

Group 6: People talk about a FACT

Group 7: Affective reaction to a FACT

By observing these semantic sequences, Hunston (2011) describes three semantic motifs: (i) the "cause" motif (Groups 1, 2, and 3), (ii) the "orientation" motif (Group 4), and (iii) the "human response" motif (Group 5, 6, and 7).

On the basis of the existing studies and our observation of the data, this study investigates FACT from the vantage point of transitivity and semantics in discourse.

\section{FACT Clause and Transitivity}

In SFL, transitivity is known as the configurations which are recognized by the grammar of processes, participants, and circumstances. The transitivity system construes the world of experience into a manageable set of process types (Halliday, 1994/2000, p. 106). There are six processes in the transitivity system: material, mental, relational, behavioural, verbal and existential.

As Halliday (1994/2000, p. 269) states that FACT "is not a meaning created in anybody's consciousness, nor it is emitted by any signal source; it is simply got up so as to function as a participant in some other processtypically a relational process, but sometimes also a mental or a verbal one". Halliday's idea indicates that FACT clause typically occurs in certain process types and functions as different participant roles in these process types, typically a relational process, sometimes also a mental or verbal one. The following subsections provide a detailed analysis to these process types.

\subsection{FACT Clause in Relational Process}

The most typical environment for a FACT clause to enter into is the relational process. There are three main types of relation in the relational process in English system: intensive, possessive and circumstantial; and each of them comes in two distinct modes of being: attributive and identifying. As to FACT clause, it typically occurs in the relational clause of the intensive type, either attributive or identifying.

In an attributive relational clause, FACT clause serving as a Carrier, for example, that the authority of parliament has declined in Example (2), is usually a postponed subject, with the anticipatory it as the Subject placeholder. 
The Attribute, true in Example (2), is usually realized by a nominal group with an adjective or a noun as Head.

(2) It is true [[ that the authority of parliament has declined ]]. (CCEG: 339)

Another typical environment for a FACT clause in the relational process is the "identifying" one. FACT clause in the identifying clause, as a specific embodiment, serves as Token, which is identified with a Value realized by a nominal group with a noun as Head. The nominal group typically belongs to the class of FACT nouns such as fact, principle, proof, problem, rule, requirement, obligation, necessity, reason, and problem. For instance,

(3) The fact is [[ that a happy person makes a better worker ]]. (CCEG: 339)

Taking Example (3) for illustration, the embedded FACT clause that a happy person makes a better worker serving as Token is identified with a Value realized by the nominal group the fact. In this FACT clause simplex, the Value is an interpretation of the embedded FACT clause, identifying it as a specific FACT.

Combining the above analysis of FACT clause both in attributive clause and identifying clause, we can find that FACT clause in the intensive relational clause functions as the participant role, either as the Carrier or the Identified/Token.

\subsection{Fact Clause in Mental Process}

Mental process is the process type of sensing. As is pointed out by Matthiessen (1995, p. 261), the type of metaphenomenality depends largely on the types of sensing: cognitive, desiderative, emotive or perceptive. It is the type of sensing that is the crucial element which determines the metaphenomenon as a FACT or an idea. The most common mental environment for a FACT is that of emotion or cognition. The emotive or cognitive processing is activated by or constructs a response to a FACT. For example,

(4) I really resent the fact [[ that I have been labelled a bad mother because I smoke ]]. (BNC K5M 11020)

In Example (4), resent is an emotive verb, and the FACT clause that I have been labelled a bad mother because I smoke is Phenomenon. The existing studies (e.g., Matthiessen, 1995; Halliday \& Matthiessen, 2004) have shown that the emotive type with a FACT clause as Phenomenon is more common, in which the Phenomenon is explicitly construed as an Agent bringing about the Senser's involvement in the process of emotion.

The discussion of FACT clause in mental process presents that the rankshifted FACT clause functions as the pre-existing Phenomenon typically in the emotive or cognitive mental process, in which FACT is not brought into existence by the Senser, instead the Senser reacts to FACT.

\subsection{FACT Clause in Verbal Process}

Similar to the situation in which a FACT clause is downranked into a mental process, it occurs in a verbal process without being projected by it. But the occurrence, comparatively speaking, is obviously less than that of FACT clause in relational or mental process. For example,

(5) We also mentioned the fact [[ that we don't go round the sun in exactly three hundred and sixty five days ]]. (BNC KPA 1936)

In verbal process, the embedded FACT clause, for example, that we don't go round the sun in exactly three hundred and sixty five days in Example (5), is ascribed to as Verbiage which is "the function that corresponds to what is said, representing it as a class of thing rather than as a report or quote" (Halliday \& Matthiessen, 2004, p. 255). In the clause, the explicit Sayer, We in Example (5), does not bring FACT into existence. Equally, FACT pre-exists the process.

In practical language use, a more common environment for a FACT clause is an impersonal verbal process, for instance, it is said that..., it is rumored that..., it is noted that..., in which a FACT clause enters into without explicitly indicating the Sayer. For example:

(6) It should be noted [[ that the majority of employees posted abroad are men although the number of women executive expatriates is increasing ]]. (BNC CHS 1319)

From the transitivity analysis, we can see that the embedded FACT clauses play different participant roles in different processes, such as, the "Phenomenon" in mental process, "Verbiage" in verbal process, "Carrier" or "Token" in relational process. In Halliday's understanding, the process is not really a process at all, "but simply a way turning a FACT into a clause" (Halliday, 1994/2000, p. 271). By the process, the speaker only wants to make sure the FACT status in it, describing its objective existence. Despite that FACT as an objective proposition is not brought into existence by the Processer of the clause simplex, it is involved with the consciousness semantically. The analysis of FACT in different process types indicates either the speaker consciousness or the Processer consciousness or both of them are involved in the FACT proposition, which is 
discussed in the following section.

\section{Discourse Semantic Account of FACT}

This section is an investigation of FACT from the vantage point of semantics in discourse with three semantic models: (i) positive/negative orientation model; (ii) positive/negative reaction model; and (iii) positive/negative evaluation model. More crucially, how these semantic models are construed by the contextual factors as well as the different process types from the perspective of experiential function in SFL is envisaged during the investigation.

\subsection{Orientation to FACT}

The semantic model of positive or negative orientation provides discourse context in which FACT clause enters into with the FACT proposition accepted or rejected, being aware or unaware, admitted or denied etc.

In terms of transitivity, this type of situation lies in the cognitive mental process and verbal process, for example, He accepted the fact that..., I admit the fact that..., We recognize that.... In these processes, both the speaker consciousness and the Processer consciousness are involved. The FACT proposition is first committed by the speaker who believes its existence. Then the Senser or Sayer represents some reactions to the proposition, such as accepting or rejecting. This type of FACT is grouped into the FACT involving both speaker and Processer consciousness, or s-P-FACT.

The semantic model proposed here is not only related with the process types of FACT clause simplex, but also related with the contextual factors, i.e. the preceding and subsequent orthographic sentences. Take the following example as an instance.

(7) $[1]^{1}$ The Libertarian Ideal is seductive. [2] Previous studies have repeatedly drawn attention to the fact that voters, particularly those who read lowbrow tabloids, tend to believe the news on television but remain sceptical about what they read in the press. [3] Our study confirms that finding but questions its relevance and its implications. [4] Despite their scepticism, readers said they found the press useful, particularly for guiding their voting decision if not for providing information. [5] Academics regard bias as a sin, but others may regard it as a virtue. (BNC A62)

In this discourse, the use of the process type in Sentence [2] have repeatedly drawn attention to indicates that the speaker is subscribing to the FACT proposition "the fact that voters, particularly those who read lowbrow tabloids, tend to believe the news on television but remain sceptical about what they read in the press" to be existent before Previous studies come to accept it. The FACT proposition in Sentence [2] is an interpretation for the topic sentence of this paragraph The Libertarian Ideal is seductive in Sentence [1]. This position is further argued by the following sentences, such as our study confirms ... but questions ... in Sentence [3], readers said they found the press powerful in Sentence [4] and others may regard it as a virtue in Sentence [5].

The discourse context of "positive" orientations are usually expressed by the cognitive mental process or verbal process, such as accept, realize, admit, prove, be conscious of, be aware of, come to terms with, be confronted with, be struck by, draw attention to. Discourse contexts of "negative" orientation are also manifested in the Predicators such as disregard, neglect, overlook, ignore, resent, avoid, obscure, be unaware of....

\subsection{Reaction to FACT}

In this semantic model, the positive or negative reaction mainly comes from the Processer. The discourse context in this situation is that FACT impinges on the Processer who reacts in an emotional manner, such as surprise, sadness, pleasure, worry, happiness and so on.

Such reaction includes positive or negative emotional reaction to the objective existent proposition. This kind of discourse schema is typically associated with the emotional mental processes or attributive relational processes in terms of transitivity. Specifically, the Senser in mental process is construed as being endowed with consciousness clauses. The phenomenon of consciousness can be construed either as a quantum of change flowing from our consciousness or as impinging on it. Therefore, in some emotive mental processes, for example, I regret that..., we rejoice that..., and some attributive relational processes, for instance $I$ am surprised that ..., I am happy that..., I am sure that..., She was sad that..., It is obvious to me that..., there is the explicit consciousness involved. In this situation, the FACT proposition is obviously related with the Processer although the Processer just reacts to the proposition without creating it. We group FACT in this situation as Processer consciousness FACT or P-FACT. The following is an instance of P-fact in discourse:

(8) [1] Interruption denies the buyer the kind of respect he is entitled to receive and may lead to a misunderstanding of the real substance behind the objection. [2] The correct approach is to listen carefully, 
attentively and respectfully. [3] The buyer will appreciate the fact that the salesperson is taking the problem seriously and the salesperson will gain through having a clear and full understanding of what the problem really is. [4] This approach maintains the respect the salesperson shows to the buyer. [5] The salesperson first agrees that what the buyer is saying is sensible and reasonable, before then putting forward an alternative point of view. [6] It therefore takes the edge off the objection and creates a climate of agreement rather than conflict. (BNC K94)

In the above discourse, the buyer in Sentence [3] as the Processer shows his positive emotional reaction (appreciate) to the proposition the fact that the salesperson is taking the problem seriously and the salesperson will gain through having a clear and full understanding of what the problem really is and perceives it as a FACT. The reaction to this proposition is further explained in Sentences [4] to [6]. In terms of the speaker, his attitude or idea does not play an important role in the interpretation of the text. Therefore, in this situation, it is for the Processer that the proposition in that-clause is a FACT. Hence, in this mental emotional process type of discourse context, it is the Processer who treats the proposition as FACT and the already existing FACT in turn impinges on the Processer's consciousness. But as to the speaker, the proposition is not necessarily a FACT.

\subsection{Evaluation of FACT}

The semantic model of evaluation of FACT involves the evaluation from the consciousness of speaker. This kind of discourse context is usually being attributed to the FACT proposition by "impersonal" expressions, such as ...be significant, ...be amazing, ...be striking and so on.

The explanation of this semantic model is associated with the observation of relational process, in which FACT is not construed as a phenomenon of consciousness; rather, it is construed as one element in a relationship of being. As is investigated, most of the relational processes in which FACT clauses occur are "impersonal", for example, it is true that..., it was obvious that.... In these clauses, FACT construed as a participant is configured with another relational participant that has to come from the same semiotic domain of being. So, there is no consciousness endowed. The only consciousness on which the FACT proposition can rest is the speaker's consciousness. Therefore, the FACT proposition in the impersonal relational process, attributive or identifying, is speaker-committed, or is referred to as s-FACT.

This semantic model is closely related with the evaluative meaning and bi-polar subclassification of evaluative meanings. For example:

(9) [1] I want to argue that three features of the global economy suggest a possibility of using the influence of existing power systems to begin such a process of reorientation. [2] First is the fact that the geography of economic globalization is strategic rather than all-encompassing, and that this is especially so when it comes to the managing, coordinating, servicing and financing of global economic operations. [3] If it were only natural resources that have such a strategic geography, the options for using the power of power would be severely curtailed. [4] The fact that it is strategic is significant for a discussion about the possibilities of regulating and governing the global economy. [5] Second, the center of gravity of many of the transactions that we refer to in the aggregate as the global economy lies in the North Atlantic region, a fact which also facilitates the creation and implementation of convergent regulatory frameworks and technical standards. [6] Hence developing alternative regulatory framings and standards should be enabled by the fact of this concentration in the North Atlantic. (COCA)

In this discourse, the FACT clause the fact that the geography of economic globalization is strategic appears in Sentence [2]. Then, it is further evaluated as significant in Sentence [4] which indicates the speaker's manner. This reaction model is closely related with the impersonal relational process which carries the evaluative meaning.

Bedsides the evaluative proposition which is indicated from the speaker's orientation, the discourse context also produces other types of semantic propositions, such as "addition" in Example (10), "causality" in Example (11) and others.

(10) Sluggish growth, high unemployment, and increasing income disparity playing out against the background of a mounting fiscal crisis means, surely, that a perfect economic storm is brewing - a storm unlike anything seen in America since the 1930s. Add to this the fact that emerging economies unburdened by anything like the fiscal drag the United States suffers from are competing with us for both resources and markets, and you have, it would seem, a recipe for economic - and therefore social and political - disaster. (COCA)

(11) Frequently, electronic services will enable metadata exchange in $D C$, but the fact that DC is not strict a standard can cause problem in metadata interoperability. However, the metadata defined by this format are a 


\section{subset of metadata defined by MARC 21. (COCA)}

The presentation of these semantic models provides the general discourse context for our discussion. The above analysis suggests that the expressive meaning of FACT proposition is closely relevant to the lexicogrammatical pattern of FACT, especially the Predicator in the process type in terms of transitivity, and its discourse context. The relationship among them is summarized in Table 1.

Table 1. The semantic models of FACT in discourse context

\begin{tabular}{|c|c|c|c|c|}
\hline \multicolumn{2}{|c|}{ semantic models } & \multirow[b]{2}{*}{$\begin{array}{l}\text { Predicator } \\
\text { admit..., accept..., be conscious } \\
\text { of..., be aware of..., } \\
\text { come to terms with..., be } \\
\text { confronted with..., be struck } \\
\text { by... }\end{array}$} & \multirow{3}{*}{$\begin{array}{l}\text { Process types } \\
\text { verbal: indicating } \\
\text { mental: cognitive }\end{array}$} & \multirow{3}{*}{$\begin{array}{l}\text { FACT types } \\
\text { s-P-FACT }\end{array}$} \\
\hline \multirow[t]{2}{*}{ orientation } & accepting & & & \\
\hline & rejecting & $\begin{array}{l}\text { disregard, neglect, overlook, } \\
\text { ignore, avoid, obscure }\end{array}$ & & \\
\hline \multirow[t]{2}{*}{ reaction } & positive & rejoice, please, be surprised & \multirow{2}{*}{$\begin{array}{l}\text { mental: emotive } \\
\text { relational: intensive \& } \\
\text { attributive }\end{array}$} & \multirow[t]{2}{*}{ P-FACT } \\
\hline & negative & resent, regret, be sad & & \\
\hline \multirow[t]{2}{*}{ evaluation } & positive & $\begin{array}{l}\text { be significant, be amazing, be } \\
\text { important }\end{array}$ & \multirow{2}{*}{$\begin{array}{l}\text { Relational: intensive \& } \\
\text { attributive }\end{array}$} & \multirow[t]{2}{*}{$\mathrm{s}-\mathrm{FACT}$} \\
\hline & negative & $\begin{array}{l}\text { be improper, be unfortunate, be } \\
\text { unlucky, be doubtful }\end{array}$ & & \\
\hline
\end{tabular}

It can be inferred from that above analysis that the expressive meaning of FACT in discourse context indicates the abstract feature of FACT proposition that is objectively pre-existent to the process in which it participates. In turn, it is the process type that determines the expressive meaning of FACT clause. Its implicitness allows its FACT status to be inferred as a matter of either the speaker or a second consciousness, or both. Therefore, the analysis verifies that FACT is an "objective existence" in SFL.

\section{Conclusion}

In this study, we have investigated FACT from a discourse perspective. The transitivity analysis displays that the embedded FACT clauses function as different participant roles in different processes, such as, the "Phenomenon" in mental process, "Verbiage" in verbal process, "Carrier" or "Token" in relational process. The transitivity analysis, on the one hand, lays a solid theoretical foundation for the semantic analysis; and on the other hand, indicates either the speaker consciousness or the Processer consciousness or both of them are involved in the FACT proposition. Then, the semantic account of FACT in discourse offers three major semantic models in FACT: orientation, reaction and evaluation, and all of them are bi-polar. The semantic account also envisages how the expressive meanings of FACT are construed by process types and contextual factors. From the analysis, we can conclude that the semantic models of FACT are closely related with its lexicogrammatical patterns, so as to verify the principle that meaning is realized by form and form realizes meaning in SFL.

\section{Acknowledgements}

I would like to express my greatest respect and gratitude to my supervisor, Professor Zeng Lei, for her professional counsel and direction in my $\mathrm{PhD}$. thesis on which this present study is based.

\section{References}

Butler, C. S. (2003). Structure and Function: A Guide to Three Major Structural-Functional Theories, Part 2: From Clause to Discourse and Beyond. Amsterdam: Benjamins. http://dx.doi.org/10.1075/slcs.64

Davidse, K. (1994). Fact projection. In K. Carlon, K. Davidse, \& B. Rudzka-Ostyn (Eds.), Perspectives on English: Studies in Honour of Professor Emma Vorlat (pp. 257-284). Leuven: Peeters.

Davidse, K. (2003). A corpus check of the factive presupposition. In A. Remael \& K. Pelsmaekers (Eds.), Configurations of Culture: Essays in Honour of Michael Windross (pp. 115-127). Somersstraat: Garant.

Eggins, S. (2004). An Introduction to Systemic Functional Linguistics (2nd ed.). London: Continuum.

Firth, J. R. (1935/1957). The technique of semantics. Transactions of the Philological Society, 34(1), 36-73. Reprinted in J. R. Firth (Ed.), Papers in Linguistics 1934-1951 (pp. 7-33). Oxford: Oxford University Press. 
Forey, G. (2009). Projecting clauses: interpersonal realization of control and power in workplace texts. In G. Forey \& G. Thompson (Eds.), Text Type and Texture (pp. 151-174). London: Equinox.

Francis, G. (1993). A Corpus-driven approach to grammar: principles, methods and examples. In M. Baker, G. Francis, \& E. Tognini-Bonelli (Eds.), Text and Technology: In Honour of John Sinclair (pp. 137-156). Amsterdam: Benjamins. http://dx.doi.org/10.1075/z.64.10fra

Halliday, M. A. K. (1994/2000). An Introduction to Functional Grammar (2nd ed.). London: Arnold / Beijing: Foreign Language Teaching and Research Press.

Halliday, M. A. K., \& Matthiessen, C. M. I. M. (2004). An Introduction to Functional Grammar (3rd ed.). London: Arnold.

Hunston, S. (2011). Corpus Approaches to Evaluation: Phraseology and Evaluative Language. London: Routledge.

Hunston, S., \& Francis, G. (2000). Pattern Grammar: A Corpus-driven Approach to the Lexical Grammar of English. Amsterdam: Benjamins. http://dx.doi.org/10.1075/scl.4

Matthiessen, C. M. I. M. (1995). Lexicogrammatical Cartography: English Systems. Tokyo: International Language Sciences Publishers.

Quirk, R., Greenbaum, S., Leech, G., \& Svartvik, J. (1972). A Grammar of Contemporary English. London: Longman.

Thompson, G. (1994). Propositions, projections and things. Paper Presented at the 21 st International Systemic Functional Congress. August, 1994. Gent, Belgium.

\section{Note}

Note 1. In SFL, "clause" is used to express a single proposition. Here, the term "sentence" is used to refer to the unit of orthography. The orthographic sentences are numbered with Roman numerals for the convenience of discussion.

\section{Copyrights}

Copyright for this article is retained by the author(s), with first publication rights granted to the journal.

This is an open-access article distributed under the terms and conditions of the Creative Commons Attribution license (http://creativecommons.org/licenses/by/3.0/). 